\title{
South African MBA's Must Focus on Development Issues not Business and Finance Only and Must Redefine the Dominance of the Eurocentric Approach
}

\author{
Anis Mahomed Karodia (PhD) \\ Professor, Senior Academic and Researcher, Regent Business School, Durban, South Africa \\ akarodia@regent.ac.za \\ Dhiru Soni (D.Phil) \\ Professor and Director of Research, Regent Business School, Durban, South Africa \\ dsoni@regent.ac.za
}

Doi:10.5901/mjss.2014.v5n27p108

Abstract

Purpose: The purpose of this paper is to emphasize the critical need for the inclusion of development, cultural and social issues within the MBA curriculum of South African Business Schools. Hitherto, South African Business Schools have copied the models engineered by European and Western Business Schools. This was largely due to the imposition of Western models of education in South Africa, due to the policies of repressive colonialism and of apartheid. Given the all embracing reality that the fundamentals of business education must not be compromised in articulating the core curriculum of the MBA because, of its universal application and acceptability. The call in this paper is that South African Business Schools must begin to think out of the box, not mimic, all aspects of Western models and attempt to focus on the global political and African economy with particular reference to development, cultural and social issues that permeate African educational discourse. Global and national South African rankings use a range of indicators to rank universities. Many of these criteria are abstract and not relevant to the so - called 'Third World" but, in reality should focus more on the many important and critical development challenges that confront South Africa and African countries in general. It is therefore, a clarion call to South African higher education authorities and, to the administrators of the South African Association of Business Schools, and the African Association of Business Schools (controlled largely by South African White functionaries), including the administrations of the traditional white South African Business Schools of universities, to engage with the wider South African and African community, and not to solely rely on business research initiatives, but to meet the requirements of South Africa's and the continents development and social needs. The paper therefore, outlines the major objectives of critical management studies which must be included in the MBA programme in South Africa which has been paid scant reference to in the past and continues to do so. It also enunciates the importance of culture to MBA teaching and its impact on technology. The paper very briefly articulates and underscores the thesis that, Western interpretation of education models, Western technology and political domination have served to hinder rather than help African economic growth. Design / Methodology / Approach: The paper does not use the traditional methodology used in classical research, but attempts to synthesize the thought processes of the writers from observation and experience with particular reference to South Africa. However, the researchers use some literature to garner their thoughts, in order to examine the issues raised in this paper. The paper does not aim to capture all issues that permeate this controversial and debatable issue, but attempts to place this crucial issue on the agenda of MBA programmes in South Africa and the continent, in order to stimulate reasoned discussion. Findings: There are no explicit findings that emanate from this paper and discussion. The findings are therefore dispersed throughout the discussion in this paper. However, the distinct findings, conclusions and recommendations are made at the end of the paper. These are synthesized through observations, experiences and the critical thinking within the ambit of the paper, which indicates an overt bias and thinking in South African MBA programmes, which are heavily loaded towards a Eurocentric bias. This bias has therefore, led to a lack of appreciation of the developmental dynamics and socio - economic realities that confront South Africa, post 1994, given its historic past and, the challenges that confront the continent of Africa, since 1957, when Ghana became the first African country to gain independence. It is against this background that the discussion in this paper is formulated and discussed. Originality Value: The original value of this paper exemplifies the reality of thinking out of the box and, in some ways challenges the status quo in terms of the subject matter taught in MBA programmes in South Africa and, the continent of Africa. The paper therefore, calls for new thinking and remedial action, in terms of the course offerings within traditional MBA university programmes, in South Africa in particular.

Keywords: Colonialism; Apartheid; Globalization; Development; Business Education; Business Associations, Continent, University; Independence; Technology 


\section{Introduction}

The European scramble for the wealth of Africa has impoverished its resources, not only through exploitation of labour and mineral resources, but through a system of political domination and technological superiority that has made Africa dependent on Western know how. This situation continues even today in the 21st century through the ravages of colonialism, political and economic exploitation and through globalization reinforced by neocolonialism and neoliberalism. Economic dependency of Africans has thus been maintained together with the underdevelopment of Africa. All of this therefore, reflects a growing trend in Afrocentric scholarship to remove the blame from the victims. It is against this background that both basic and higher education was modeled in Africa by both Anglophone and Francophone colonial countries. There are many, who are guilty of furthering this pervasive system and include government bureaucrats, new settlers who still control some facets of higher education, past white settlers who are South African citizens, politicians and others who serve corporate interests of Europeans and Western corporates. Business is controlled largely by these corporates, who fund Business Education Institutions and programmes, provide large endowments to selected Business Schools who are essentially steeped in the historic colonial and apartheid past, and are thus in a position to maintain the status quo, with the greatest impunity.

South Africa and Africa, particularly Business Schools must debate the problems of 'Third World' development. Business Schools in South Africa must therefore reject the bourgeois sociologists' explanation of "Third World' under development. MBA Schools and their administrations including the Association of South African Business Schools and the African Association of Business Schools, must take the responsibility of taking the lead to discuss this vexing issue and, usher in a new era in the recurriculation of MBA programmes offered on the continent. The dependency model in respect of higher education must be placed high on the agenda of discussions. Something has to be done to ameliorate our present education circumstances and conditions of Africa's and South Africa's, under - development. The methods and techniques used to accomplish our exploitation must be fully comprehended. The "phantom bourgeoisie" as Frantz Fanon has referred to "because these collaborators or compradors advance our exploitation in Africa, which has reached monumental proportions" (Offiong, 1982: XI) and continues unabated into the 21st century. In this regard, Africa has to:

- Undertake a systematic survey in respect to development and utilization of its physical and human resources and the formulation of true development plans for maximum mobilization of its education potential at all levels of business and, its domestic resources.

- An improvement in the machinery of administration, in education and other institutions and a redirection of science, technology, and business by giving specific attention to entrepreneurship outcomes.

- The MBA degree must concentrate on the above issues including more vigorous growth strategies for purposes of increasing export earnings and concentrate on an increased and assured flow of capital.

Rich nations of the West have tended to stall on trade liberalization and monetary reform because they want these matters dealt with, within the context of the General Agreement on Tariffs and Trade (GATT) and, - now called the World Trade Organization - WTO), and International Monetary Fund, both bodies strongly under their control. These issues have to be clearly raised within MBA programmes in Africa. They are yet to agree on market sharing, whereupon they would allocate a proportion of their markets to under - developed countries by reducing their own protected production. Fundamentally, the disillusionment lies in the fact that a great part of economic imperialism is counterproductive, in relation to the actual goals of development, because the tendency is to supply it to regimes which want to promote quantitative economic growth through rapid industrialization, which tends to benefit the internal elites of African countries and, their international allies, than to carry out social reforms which benefit the masses. Issues of this nature have hindered the advancement of development goals that ought to be raised in the syllabus of MBA programmes, because they tend to distort the analytical parameters that are required by African MBA students. It has to be understood that, those who "employ the theory of imperialism have as concepts such terms as dependency, neocolonialism, liberation, exploitation, late capitalist societies, or societies in the stage of monopoly capitalism" (Berger, 1976). At another level the instrumentation of the theory of modernization has been derived from a convergence of sources in the social sciences in the Western societies over a long period of time.

Most contributions have come from economists who have provided descriptions and explanations of the great transformations that first initiated the industrial revolution in the West. Similar contributions have been made by sociologists who have meticulously described and explained the enormous transformations that occurred in the non economic institutions of these societies. In this regard Offiong (1982: 14) states that "What modernization theorists most often end up with is an eventuating ethnocentric practical recipe which admonishes poor societies to leap into the $21^{\text {st }}$ century. In other words, join the Calvinistic cult and you will experience a sudden leap into modernity." This is what has developed in academic discourses in Africa and South Africa in particular, due firstly because of colonialism and the 
ruthless Calvinistic approach under apartheid in South Africa and, many of its premier universities, such as the former Universities of Potchefstroom (North West University today), Stellenbosch University, Pretoria University, Rand Afrikaans University (University of Johannesburg today), University of Natal (University of KwaZulu - Natal, today), including a number of former Technikons (incorporated as Universities today) and the former homeland black universities that are steeped in the traditions of Christian Higher Education with a very strong Calvinistic bias.

This apartheid bias lingers on and still influences academic discourse in many fields of academic engagement and, to this end the education status quo is maintained and curriculum at these institutions are engineered by academics that push a Eurocentric, Calvinistic and Christian approach to education. The MBA degree is no different at most traditional universities in South Africa, given the history and legacy of apartheid. These universities are also dominated by Europeans from outside, with particular reference to MBA programmes and dominate the discussions within the South African Association of Business Schools and the African Association of Business Schools.

This is clearly exemplified by the all embracing reality and fact as to how many of the historically advantaged former apartheid public universities, which are supported in large measure by corporates, in the form of large monetary endowments, running into millions of rands. These universities within their MBA faculties elect their chairpersons and among them is also the chairperson of the African Management Institute (AMI), and subsequently the same individual I person (A Eurocentric outsider and new settler) was also elected as the chairperson of the African Association of Business Schools and up to 2014 was the current chairperson. It is obvious that they are thus able to manipulate the MBA discourse on the African continent also. This is exemplified by them being supported by the corporates and are, therefore, able to muster large monetary inputs to suit their parochial agendas and steer the MBA discussions on their terms and, in the interests of the corporates and thus consolidate the capitalist and neoliberal agenda in Africa. They lead from the oppressive front to keep all others out of the game, as though they only have the right to express opinion on all business and political issues on the continent and particularly South Africa. This is further exemplified by the reality that, when opinion is required on any political, economic, social and business issue by governments and the private sector including the corporates, particularly in South Africa, the former White public universities offering MBA programmes are most often or almost always invited to make comment and afford advice in the media and the radio. This has to change and the continent of Africa and South Africa has to wake up to the reality that there are African intellectuals and opinion makers amongst their ranks within historically disadvantaged and private universities / colleges, because a new type of colonial education oppression is being created within the education discourse of South Africa and the continent as a whole.

In a recent exchange of letters concerning agricultural discourse in Africa, as instructed by the South African Association of Business Schools, to participate and tour Africa, one of the authors (black) of this article had written to the Secretariat of the South African Association of Business Schools, to be included on a team discussing agricultural issues from a business perspective but, was excluded, without reasons, in spite of the fact that he was highly qualified in agriculture, with over twenty years of agricultural experience and that his PhD degree was on agriculture, he had produced many agricultural research papers and, that his initial qualification was a veterinary degree and, also held a veterinary epidemiology degree from the United States, and possessed further academic studies in agricultural veterinary extension education from the University of Minnesota and, was a certified inspector of the United States Department of Agriculture. All of this was ignored by the association. Later, to find out those individuals with no agricultural experience were involved in debating and setting the agenda in respect of agricultural business for South Africa and toured Africa and presented to conferences on the continent. This is the state of play in South Africa, and such behaviour goes unchallenged and, the status quo is maintained by keeping the "white MBA boys club" intact. The strategy is simple exclude all others because according to them, they have nothing to contribute. This condescending attitude must be stopped in its tracks or South Africa and, the African continent will rue its decision not to challenge the status quo. The time has come that Africans and South African blacks must assert themselves, takes the moral high ground and must now take up leadership positions in these associations. Africans can no longer be apologists to injustices perpetrated upon them by outsiders in the main, given Africa's colonial history. In this sense the ideological make up of apartheid still permeates their discourses very strongly and, all else does not matter.

It has to be articulated within the MBA programmes of South Africa and Africa as a whole that the "theory of imperialism, derives its concepts from Marxist sources. The wealth and poverty of nations result from the modern global process of exploitation. In this regard, Andre Gunder Frank (1982) refers to this situation as "the development of underdevelopment." The problem of the poor countries is not the lack of education or the lack of business and technological know - how, cultural traits conducive to development or modern institutions or for that matter entrepreneurial ability, but that they have been subjected to the exploitation of the international capitalist system and its agents both domestic and international. "The MBA in Africa therefore, has to place these issues squarely on the table for 
proper analytical understanding, in respect of the underpinnings of the global political economy, because of the infiltration of Western capital into poor developing countries, which has resulted in situations characterized by economists as "growth without development" (Karodia. 2013).

On the other hand Frank (1969) outlines that "The concept of 'dependency' coined by Brazilian sociologist Fernando Henrique Cardoso helps to link both economic and political analysis; that is, it links those who are the beneficiaries of development with those who make the decisions. Dependency simply states that crucial educational and economic decisions are made not by the countries that are being 'developed' but by foreigners whose interests are carefully safeguarded. Foreigners use their economic power to buy political power in the countries that they penetrate." We have seen this happening in democratic South Africa, post 1994, for example, the Guptagate scandal, the arms deal, the Vrede dairy project, Lonmin, The Marikana Massacre during the protracted five month wage strike most recently, were the government has been complicit, multinationals, large corporates who imbibe the so - called minority of blacks and mainly corrupt politicians and bureaucrats, through a misguided black economic empowerment policy that, has favoured only, a few of the black predatory elite, at the expense of the majority black population. This has also been the situation in African countries post African independence and, this situation continues unabated into the $21^{\text {st }}$ century. The time has come to address this situation very seriously and the MBA prograame is one vehicle that can do so, in terms of addressing this problem within the ambit of the MBA curriculum.

All of this has been given tacit acceptance by the government. The upper echolons of the South African Association of Business Schools is dominated by new and old settlers and, is mainly white with, a few blacks, to add 'colour' to the scheme of domination. This collusion between alien economic and political power distorts education imperatives in Africa, including South Africa and also the economy and the policies of dependent countries. Out of this situation emerge political alliances between the domestic and foreign bourgeoisie. The process is now complete because just as the metropolis exploits the colonies, so does the domestic colonial bourgeois class, exploits the rest of the population. It is therefore fundamental, to understand the theories of development in great detail and as to how globalization, and social issues affects the sound understanding of business modalities that, in turn affect development of so - called "Third World" countries and, distorts the minds of local intellectuals who are taught the MBA programme within the confines of the former white apartheid university establishments, on the basis that, one either ships in or ships out of the education business system. This destroys morale and the self - worth of black students, twenty years down the road of South African democracy and after, fifty seven years of African independence. In this regard South African and African students must explore the MBA discourse from the perspectives of understanding and, critically analyzing that imperialism is the highest stage of capitalism. Further, that it has to be taught and fully comprehended that the development of England, for example, was assisted by the exploitation of India and Africa. The world is replete with examples of this nature. It destroys the business emergence of Africa, as a whole.

The issues raised above are only the tip of the iceberg in terms of colonial and apartheid dominance for over three hundred and fifty years, in respect of the underdevelopment of Africa; and of education and the historical formulation of MBA programmes, which excluded African students entry into such education programmes and, decided that they pursue theological, legal and education courses and degrees in the main. This also applies to the recurriculation of the MBA programme, its teaching, admission requirements, very high tuition fees charged, the accepted core subjects by all business schools in the country, dominated by white academics and their gate keepers. It must broaden the minds of African students, in terms of placing the issue of development and intricate social issues that impact directly upon the type of MBA graduate that needs to be produced in South Africa, and Africa as a whole. The type of graduate produced must be versed in his / her history, the history of Africa and it's exploitation by white settlers through colonial and apartheid imperatives. In understanding these issues, business schools on the continent must produce a graduate that can meet the needs and requirements of a world affected by globalization, by facets of racism and marginalization, in order to challenge the discourse, contribute to business acumen generally and advance the historically marginalized and disadvantaged black students of the country. This must be done and undertaken, on the basis of a very wide understanding and comprehension of the African condition, which has been historically stymied by Eurocentric thinking, domination and economic exploitation.

This must allow for the emergence of a new MBA graduate that, can and must contribute to the development of the economy, grow African businesses, attempt to open their own multinational companies, challenge the stereotyping of blacks, contribute to the academic discourse by not being under the tutelage of white intermediaries and by their domination, in terms of understanding the importance of the MBA to all aspects of business, social and development life. Given the all embracing reality that apartheid South Africa denied blacks from entering this field of study and therefore, very easy for the gatekeepers, to maintain the status quo. Black graduates must emerge from this subjugation and hold their own amidst their peers and, they have the ability to do so and also challenge the status quo. The MBA in South 
Africa must be in a position to create and produce a graduate that will possess all the attributes to understand development and the oppressive history of South Africa, which affected blacks and, to make a significant contribution to business development, in South Africa and, aim to become the leader in Africa, in respect of MBA teaching and learning, and simultaneously in terms of business acumen, keeping in mind that, it is possible to create our own corporates and business incubators. This can only be done, if the MBA graduate is exposed to Africa's history and its development and, social issues that confront the continent of Africa and which has stymied its emergence and development, as a people and as a continent. Africans need to demystify the myths of white settlers terming the continent, as a 'black' and 'dark' continent, even in the $21^{\text {st }}$ century.

Berger (1976) defines modernization as "the institutional and cultural accompaniment of growth and further defines development as "good growth and desirable modernization." It therefore has to be appreciated in development discourse and, within the confines of the MBA that, modernization and development are intertwined processes, one reinforcing the other. Thus for the MBA curriculum the researchers see it on the basis that, modernization involves a complex of changes in institutions or societies and, in this sense, it involves the requirement of MBA controlling institutions and regulatory authorities to promote the betterment of all citizens, without necessarily involving the treatment of modernity and tradition as polar opposites. It must be geared towards African business and indeed aimed at African solutions within business in the continent. In other words the MBA must "incorporate new ideas into its teaching system, it must be geared towards social change, in order to produce sound leadership, capable entrepreneurs, high levels of living through modern production methods and improved social organization and, this can only be achieved by engaging the global political economy in strategy imperatives" (Rogers, 1969).

Thus before African countries can know growth and development according to Rodney (1974)) "there must be a profound analysis of Africa's position in the global economy and stratification of power, including the growing complexity of Africa's class structure" and South Africa's economic dominance by the white minority population that has historically dominated all aspects of life. The MBA programme must fully appreciate and teach that underdevelopment is not the absence of development, but it makes sense only as a way of comparing levels of development. In this regard Rodney (1974) points out that "underdevelopment is very much tied to the fact that human social development has been uneven, and from a strictly economic viewpoint some human groups have advanced further by producing more and becoming wealthy and, by the processes of exploitation of indigenous people" This can only be achieved through sound higher education. In this sense the South African Higher Education scenario, post 1994 has failed the country and its people and, so has the MBA programmes of many of the former historically white dominated MBA faculties, who set standards at their own whim and fancies, pitch the fees too high, in spite of large government subsidies, thus not allowing free and open access to black students in general. This is a cause for serious concern and has to be addressed rapidly by those concerned. In addition, they have the resources to muster support from the white dominated media, conduct surveys, set the agenda and marginalize those that do not fit into their clearly defined strategies to maintain the status quo. The MBA is not their prime focus, but using public university facilities, in most cases without paying rent; they have virtually privatized their undertakings and generate large sums of money through executive management programmes and from training opportunities within government and, the private sector and large corporations. They have created an unfair advantage and continue to do so with no checks and balances by regulatory institutions and mechanisms of the government. This is a new form of exploitation, a new form of creating dependency. A new form of controlling business imperatives within the country. All of this has to be looked into by the authorities concerned. It is not only the question of the recurriculation of the MBA programme in South Africa, but, it is a question of looking at development, social and systemic issues that need to be controlled, and reengineered by the authorities concerned, for the sake of addressing the manifest problems that confront MBA programmes in the country.

\section{Colonial Education in Africa}

The paper now attempts to look at colonial education in Africa. This will be undertaken as an expose that grounds the thought processes of the writers and is an indication as to how all education was formulated on the continent by the colonialists. This form of education has impacted negatively upon the psychology of African people in general and, together with apartheid education in South Africa, has hampered the growth and development of its people and the development of the country and the continent of Africa. Europeans controlled African participation in the new economic order and, they also carefully structured African education, so as to perpetuate their underdevelopment and created dependency. The colonial powers mainly Britain and France and then the racist Nationalist Party of apartheid South Africa, knew that the introduction of western education was the sine qua non for the exploitation of Africa and Africans. "Literate Africans were useful in many ways, although too much literacy was considered dangerous and undesirable. A 
certain amount of technical training was essential to provide cheap semiskilled labour, but it could not be allowed to continue beyond a given standard or the African would soon be competing with whites" (Barnet and Miller, 1974).

This was precisely what happened in South Africa under apartheid and under colonialism, in Africa. This was designed to keep the black population totally marginalized, to keep them suppressed and oppressed and, not to engage the economy; that in the initial formation of apartheid ideology, education was denied to blacks and entry into white universities was mainly denied. All of this reinforced the white man's perception that blacks were inferior citizens, who must hold menial positions and, it reinforced the master - 'slave' relationship. The psychology of the black population was so dented that, it caused an 'inferiority' complex among blacks. This was the situation that permeated and, has had a profound effect upon all education for blacks in South Africa and many parts of Africa. This is what has to be redressed by the democratic government. In reality there has to be a new intellectual policy imperative at both basic and higher education levels in South Africa to redress the education imbalances of the past. All of this has had a profound negative effect upon the praxis and pedagogy of education in Africa and more so in South Africa. The discourse of education has to be challenged because it has had a devastating effect on South Africa, in order to emerge from its past colonial and apartheid legacy. The education of the past has affected the emergence of the black population to enter the domains of business. The current MBA programmes in South Africa have to be revisited in order to give exposure to this African condition that has a profoundly negative effect and impact, upon the entry of blacks into business education and, therefore fail to understand the importance and necessity of the milieu of business education. In other words the status quo must be broken, in order to engineer a new business and education discourse. In this regard those that maintain the status quo and push the Eurocentric agenda in South African education must be engaged in respect of urgent and necessary change. If needs be they must be marginalized and excluded from the MBA discourse and discussions in South Africa. This change must be orchestrated by government, its ministry of higher education, universities, private MBA providers, business and all who are involved in higher education in South Africa.

This must be understood from the perspective that there is a tendency in South Africa by the captains of industry, the South African Association of Business Schools, by white businesses and the large corporations, including the many traditional white universities in the country to treat African societies as self - contained units, whose political, social, educational or economic systems can be analyzed in themselves; they constantly argue and assume that colonial and neocolonial imperialism, the very sources of African dependency have been such as to stimulate development. This is not necessarily true for obvious reasons. "It was the missionaries who introduced western education to the colonies to undertake menial and administrative tasks by blacks. The school was the church. The school became an evangelistic agency and the moral life and character of the Europeans was of first importance in the work of running the school. African education consisted mainly of learning the Bible, and how to read, write and calculate in English. The history of the British was taught together with European geography, Shakespeare and the works of Chaucer. All this was designed to impose upon Africans the white man's mythical superiority and the African inferiority. Africans were taught to internalize their inferiority and to recognize the white man as their saviour. As content, the schools equipped the African with little more than an elementary knowledge of the English language for an economic future in which a senior clerkship was the upper limit of his permissible advancement" (Coleman, 1982). What does all this mean?

It meant that colonial and apartheid education was not designed to benefit Africans and help, prepare them to participate meaningfully in the economic exploitation of their countries. As Nkrumah notes (In Offiong, 1982), who was the first President of independent Ghana and, the first democratically elected President in independent Africa (Ghana) in his Consciencism, "such compradors were not exposed to the kind of education that would liberate them mentally and otherwise." This was a direct reference to those African elites that played a major role to prop up colonialism and apartheid and who contributed to the oppression of blacks at the whims and fancies of the colonial master. This is precisely what apartheid achieved in South Africa and its legacy persists even today in the $21^{\text {st }}$ century. The task to transform education is therefore a mammoth task. This task is now left to the democratic governments of Africa, their public bureaucracies and their respective populations. In other words those that maintain the status quo have to decolonize their minds both, white and black South Africans, who personally gain from the exploitation of the majority black population and, it is to their benefit to keep those crying out for change completely marginalized and, within a periphery that is inconsequential to their designs.

The truth is simple, in that, the people were aware of the fact that they were being exploited and that, they did not benefit from the exploitation of their natural resources and the poor quality of their school education. They embarked on all forms of radical action to compel their white exploiters to return from where they came. But before they fled, the colonial powers imposed upon the people constitutions that would ensure conflicts among the different groups. They placed in power those who would continue to promote their interests after they had gone. The formal ending of colonial imperialism has ushered in neocolonialism. This results from 'false' decolonization, the preservation of colonial 
relationship of western dominance and African dependence by means other than direct political control. This is the reality and therefore, for South Africa and the African continent, education is vital because education is a better safeguard to liberty than a standing army. The last vestiges of white domination in education and business must be thoroughly dealt with and, it is therefore essential that the MBA addresses these issues, in order to make South Africa a winning nation. Africans need to define for themselves and, in so doing, design an education system for themselves, which will suit their conditions and, in this regard they must set the educational agenda of their countries. Having, discussed the aims of colonial and apartheid education and the African condition because of these ideological frameworks, it is now important to discuss some other issues pertinent to this debate and discussion.

\section{Academics in South Africa Must Reimagine Themselves in the Context of their Work and Society}

Given the discussion undertaken in respect of colonial education and its impact upon African societies, Paphitis and Tabensky (2014: 2) state in no uncertain terms that "Academics must reimagine themselves and their work in the context of our society. Unlike many other places in the world our academic institutions are in an ideal position to reimagine themselves creatively. However, the academic community for the most part lacks the will to reimagine ways of academic being and to recognize the rare opportunity that contemporary and democratic South Africa has to offer."

Those working in academia in the higher education sector need to ask the difficult questions: Who does education work for? and in what sense does it work? The short answer is that it works best for those who have benefitted from the status quo and who have little appetite for moving beyond long - established comfort zones. In this regard Paphitis and Tabensky point out that "the national mandate for transformation in higher education is challenging universities to reimagine themselves and their role in broader society. The potential tragedy is that if members of the academic community do not lead in reimagining the core purpose of the university, bureaucrats with narrow agendas will ultimately do the work for them, and their vision of the world will be imposed upon them." This is precisely what has happened in South Africa in terms of the MBA programme delivered by traditional former apartheid run universities and the South African Association of Business Schools that dominate the MBA landscape and are apt to maintain the status quo. The debate must be about the purposes of higher education in South Africa and beyond. It must be centered on the ideal relationship between university and society and, the current nature of this relationship, that community engagement around the country must transform. One of the central conclusions of the Rhodes Roundtable is that "a false dichotomy informs much of the South African debate on community engagement, which is a debate about the future direction of the South African tertiary sector." (Mail and Guardian, 2014: 2).

On the other hand, there are those who rightly think the South African tertiary sector could be doing much more to address transformational imperatives and that there are those who rightly think that, traditional universities should not function as non - governmental organizations, and that the proper job of academics is to research and teach, rather than to fix the woes of the country on behalf of the state. The traditional universities offering the MBA programmes together with the South African Association of Business Schools must give these aspects very serious consideration. Why is this false dichotomy? Paphitis and Tabensky (2014: 2) state in this regard that "it requires academics and administrators to rethink and understand the academic project, in terms of understanding the role of community engagement in higher education, as John Dewey and Paulo Freire had done in the past." In this regard they have pointed out that the basic idea behind a service learning model is that true understanding is often best acquired through our interaction with the world outside academic institutions. Through service - learning activities, students gain an embodied understanding of their social and economic context and are therefore, more likely to become agents of social change, and better professionals as well. It is not merely about addressing development imperatives. It is also about improving the project of community engagement within higher education. This is what MBA programmes in South Africa must understand and take the lead in respect of transformation of South African higher education. The South African Association of Business Schools has reneged on this fundamental and important aspect of transformation because, of its narrow understanding of the South African transformation debate, and the political agenda, post 1994, in order to take South Africa forward, against all odds and, to engender a policy of equal opportunity, without any let or hindrance.

For far too long the world has seen the overt dominance of Western epistemology in academic debate, discussion and the content of syllabuses within basic and higher education in the so - called "Third World." For far too long Western epistemology has dominated the agenda of education and critical debate which has led to the reinforcing of colonial analysis, perceptions and its overt dominance, much to the peril of so - called "Third World development. The epistemology of other cultures and those defined differently to the Western world, have been relegated and disregarded because of so - called and unfounded Western superiority. This has seen the dominance of Western epistemology, as though it is the only epistemology that exists. There has therefore been a Western arrogance to almost all theory, the 
social sciences, business modalities, the sciences being grounded in Western thinking and analysis. By implication therefore, all other epistemologies can make no contribution to the world that we live in. This is a complete misnomer and this myth has to be broken and challenged on the basis that Western epistemology in reality makes up less than 25 percent of all epistemologies. The other 75 percent in reality emanates from Africa, Asia, Russia, China, Latin America and other smaller nations of colour. The time has therefore come for these epistemologies to be included in all education discourses and syllabuses and, to place these rich and relevant epistemologies that have been historically marginalized and swept under the carpet by Western dominance and thinking which has shaped education throughout the world. The time has come to place these epistemologies in the fore - front of all education discourses, debate and understandably to challenge and confront the unnecessary dominance of Western education and Western epistemology and thus break the dominance of a Western understanding and interpretation of the world.

\section{Research and Development}

In South Africa there has been a massive increase in undergraduate enrolment of students and rightfully so, given the history of exclusion, but by the same token there has been a large dropout rate from university studies, due to a poor educational background of black students and many who cannot afford the fees for university education. Most African countries according to Mohamedbhai (2014) "follow a higher education strategy that focuses mainly on increasing undergraduate student enrolment, but this needs to be approached with caution. This has brought about an increase of academic staff with increase workloads, leaving very little time for research. This has dented the quality of education. Many academics resign because of this and the poor salaries received; (and in Africa, South Africa included, they do not hold PhD degrees). This has led to poor initiation of research and a lack of experience to supervise doctoral students."

African governments can take several initiatives to improve research capacity and boost postgraduate education at both the master's and doctoral levels of studies. The MBA programmes currently have a research component attached to it. Given the current recurriculation agenda which comes into being in 2016 in South Africa, serious consideration must be given to the inclusion of research methodology within the MBA syllabus. In reality, this must become compulsory, given the new requirement, that for entry purposes the student must have obtained an honours degree. On the other hand the new MBA in South Africa will now be equated as a full master's degree and, therefore, the research component must be a stringent and coordinated approach aimed at fulfilling research capabilities and thus allowing one to proceed directly into a PhD programme. Research should be aimed at the country's development needs and all research topics at the MBA level should be aligned not only to business but also to development areas. On the other hand students must be in a position to prepare a simple and concise brief of their findings and recommendations, which must be aimed at policy makers, who are end users of this research. Regional cooperation and collaboration and networking must become an imperative in Africa for all business schools including South Africa. In other words, research must be put to practical use in order to promote sustainable growth and development and to address the magnitude of development challenges.

\section{Need for a Structural Makeover}

It has to be acknowledged that the world is changing, more importantly because of globalization and with this has come expanding mobility, access to knowledge across borders, and increased demand for higher education in developing countries. In relationship to this therefore, our understanding of new phenomena and its impacts on commerce and business education needs to be critically examined and understood" (Shaikh, Karodia, Hay and Soni, 2014: 1). What then should be the scaffolding of the new MBA programme within the context of commercial transactions, upon commerce and business education in terms of its theoretical and philosophical foundations and underpinnings? There is no doubt that the process of globalization has contributed towards the integration of the contemporary world through the flow of technology, economic activity, knowledge, values, ideas, the IT revolution. These have all impacted on the production, dissemination of information and the use of knowledge in ways hitherto unknown. Knowledge gained knows no frontiers and is borderless because it is the new 'knowledge society. Thus it is essential that the Master of Business Administration (MBA) which is a flagship education programme for the business world must transform itself. In other words the new MBA should champion an epistemology and pedagogy which firmly and strategically outlines a new pathway for teaching and learning.

Shaikh, Karodia, Hay, and Soni (2014) state that "the curriculum of the MBA will have to consider the complexities of the new knowledge environment and ensure that the silo - based approach to teaching and learning gives way to a multidisciplinary approach. Inputs from the social and natural sciences, hitherto ignored in understanding the complexities of life must emerge as a strategic imperative. The new MBA graduate will be expected to understand that global 
economics, for example, has to be contextualized within the realm of global sociology and politics as well. As a result, global socio - economic and political perspectives become integral to business and leadership." In other words, it is almost impossible for a single cognate or discipline - based knowledge field to embrace or understand the complexities of life. It now requires interdisciplinary knowledge production. Likewise, advances in information and communication technologies encourage the emergence of entirely new communicative cultures' that are highly interactive, intuitive, more visual and spontaneous, and are very different from the academic culture which has dominated intellectual knowledge production in the west, for the past couple of centuries.

Similarly, it is pointed out by Shaikh, Karodia et al (2014: 3) that "within the context of a changing, South Africa and the narrative of Africa Rising, it is essential for a business leader, an entrepreneur or MBA graduate to understand the inextricable complex business relationships of both the 'local' and the 'global'. For just as much as the 'local' is important, a sense of what is happening globally is critical. Global political economy has become intensely complex and unlike the past, global human - made phenomena affect almost every locality in the world, even the remotest village. The recent 2008 financial crisis, for example, is a case in point. In a recent article on "Africa Rising: Doing Business in Africa" special mention was made to the importance of culture and its specific nuances in African trade. Unless the MBA graduate begins to understand the impact of the complexities and intricacies of culture on almost all aspects of life in Africa, many business ventures in Africa will not succeed. Therefore, the core of the MBA curriculum needs to provide skills to manage different aspects of business and to expose the student to real world business situations. On another front Shaikh and Karodia et al. (2014) show that "in emerging economies, the need to include the new knowledge production is even greater and that Africa, for example, needs leaders who can make their economies less dependent on the sales of raw materials and rapidly advance them towards manufacturing of goods without destroying social and environmental capital in the process. In other words, becoming agents of local beneficiation. Apartheid and colonialism paid no attention to this vital factor and therefore, the current curricula of the MBA's in respect to knowledge production skills do not come close to matching the new need of African and South African societies. The task of embracing the new mode of knowledge production and ensuring that business leaders and professionals have the skills that require taking their countries and their economies forward into a developing sustainable economy is potentially the most pressing challenge that business schools are likely to confront over the next few years. Consequently, the new MBA curriculum will have to be geared and steered from previous analysis by white academics and those steeped in the apartheid and colonial mindsets about educating students about the need to adapt in the current marketplace, in order to remain relevant and not rely on the old silo - based knowledge structures as was ingrained by the ideologies of the past, especially because everything about modern business is changing"

In the case of emerging economies, Africa, included, the conventional MBA programmes will have to make way for entrepreneur - focused programmes, where the skills of finance and accounting, marketing, as well as effective leadership are integrated and taught, in terms of the new epistemologies and pedagogies that knowledge production demands. Finding, opportunities for young people is a critical challenge for Africa, where 62 percent of the population, more than 600 million young people, is below the age of 25 (see www.bizcommunity.com /Article /196/371 /114730.html). Entrepreneurship must become an integral part of every aspiring MBA graduate. The new curriculum necessitates imparting not only the technical skills of entrepreneurship, but also the mindset of the entrepreneur.

What then should the new transformed MBA provide for? Given the major transformation that has occurred in terms of globalization, the short period of less than 60 years of African independence from colonial rule and South Africa's emergence as a free democratic country, from the yoke of apartheid oppression, the explosion of knowledge, the resultant network and knowledge societies and knowledge production. Shaikh, Karodia et al (2014) indicate that the new MBA should provide:

- "A sophisticated understanding of the influence of political, social, legal and regulatory, environmental, demographic and technological impacts on companies;

- Familiarity with legislation and formal programmes that support ethical conduct;

- Exposure to companies with high levels of integrity and responsibility;

- Dynamic learning opportunities that require integrating multiple perspectives and managing ambiguities and dilemmas at the global and individual level;

- Practical experience working through responsible business decision making;

- Greater awareness of business tools and principles with social dimensions, such as socially responsible investment criteria, social entrepreneurship and innovation;

- Exposure to an array of models of the corporation, including corporate governance structures and models of the cooperation, including corporate governance structures and models, if the corporation vis - a - vis society 
at large.

- An appreciation for the interconnected nature of business operations with government and community, and the skills to engage these external stakeholders in constructive dialogue;

- Interdisciplinary thinking across the current silos of marketing, finance and accounting, operations, organizational behaviour, and strategy.

- An ability to understand and deal with trade - offs between multiple competing business and other imperatives.

- Practice in decision making in the face of imperfect or incomplete information and under conditions of great transition that the African continent and South Africa are currently undergoing."

All of the above can only be achieved, if all those concerned with the success of South Africa and, all those involved with MBA programmes in South Africa, fully comprehend the devastating effects of colonialism and apartheid and therefore, take a quantum leap into the future by decolonizing their minds, in a sincere attempt to serve African countries to become successful and, thus assist them to become successful economies and nations, and thereby, contribute significantly to improving confidence of our MBA graduates to challenge the current status quo and, stand up against entrenched apartheid and colonial mentalities that, continue to hold African countries and South Africa at ransom. In other words the philosophy of the new MBA must be steeped in the quest to develop business managers, who will be in a position to understand the relationship between business, society and the political economy. Intrinsically involved are issues of ethics and governance, environmental and resource sustainability, justice and fairness with a view of creating successful and globally sustainable societies. The MBA graduate should be challenged to consider creating a business system responsive to the greater, rather than the minority good. This opens the door for business schools to look at shaping managers not for business alone but for shaping successful and progressive societies, through the understanding of social and development issues.

The recent financial crises has brought to the fore the issues of business ethics in managers and questions the very nature of capitalistic paradigms. What is clear according to Shaikh, Karodia et al. (2014) is that "an MBA cannot be totally seen as one size fits all. Essentially a review of 'fit for purpose' is now required for Africa and South Africa. Therefore, the graduate of the transformed MBA must not only be an innovative entrepreneur, manager and leader for the $21^{\text {st }}$ century, but also:

- An individual who comprehends the true meaning of education;

- A trailblazer addressing some of the key problems and challenges of economic development that have been caused by colonialism and apartheid and by contemporary societies;

- Someone who is multi - skilled and has transferable skills;

- A person who is sensitive and capable of leading industries and organizations, with an intrinsic understanding of the relationship between business, society and the political economy;

- One who is acutely aware of issues such as ethics, governance and environmental sustainability with a view to crating a socially just society;

- Someone who understands that business does not operate in a vacuum, but is linked to government and civil society;

- A person who understands the complexity of the real world within which business operates and is able to use multi - disciplinary approaches to deal with the challenges and problems that confront Africa and South Africa;

- Someone who is able to think critically;

- A leader who is able to solve problems under real world conditions where the luxury of time is almost non existent and demands are extensive; and

- One who is humble enough to listen carefully to all stakeholders and their concerns and able to use the information gleaned from them to bring about appropriate solutions."

In order to action the above, business schools in South Africa in particular need to challenge their own orthodoxy steeped in apartheid and colonial manifestations and goaded on by those who want to maintain the undesirable status quo inherited from a sad past of exclusion of blacks. There is therefore, the need to focus on the social consequences of their actions and accept responsibility for the business excesses and historic exclusion into the preserve of their 'clubs' which is a feature of both past and current history in Africa and South Africa. What is required is a narrative of common interest to combat the mantra of selfishness, especially one that appeals to the sense that leadership is for all not for the few. Business as usual is no longer an option. In the context of the above, a national audit of the MBA, the traditional white universities offering the MBA, its core curriculum, their modus operandi is long overdue by the Council on Higher Education in South Africa, Business School Associations, Captains of Industry, Students, Civil Society Organizations, 
Trade Unions and other important stakeholders. The charting of a pathway for a more relevant MBA considering our oppressive history and specifically in view of the nascent development trajectory of South Africa and the narrative of Africa Rising is too important to be left to those who continue to maintain the status quo and therefore, cannot be left to chance. Business education as usual is no longer an option.

Shaikh, Karodia, Hay and Soni (2014: 20) state that "there is a skills deficit in most African countries, that in South Africa management positions are dominated by whites, there are huge number of vacancies, due to the legacy of colonialism and the problems and challenges of development in the post - democratic dispensation, has led to the majority within the labour force to be unskilled and therefore unemployment is rife." Africa is definitely emerging. Factors such as favourable demographics and, a steady flow of investments, abundant resources, political and economic reforms, more democratic elections, can only contribute to a greater and stronger rate of economic development in Africa. Africa offers all the opportunities of carrying out successful business. The MBA narrative of transformation must challenge these issues and also challenge the entrenched MBA bureaucracy to change or ship out of the system and, allow those who have the passion and interests of taking South African MBA education forward and, on a path of new and required transformation, for purposes of economic growth must be allowed to contribute to new horizons, once and for all.

In this regard, the Regent Business School has opened up the brown bag seminar series which is in the second year of its making and has had a number of favourable reviews. The first semester saw comprehensive issues being discussed on 15 pertinent and important governance topics, with outside speakers and academics contributing. The second semester of 2014 incorporates the theme "Issues in Critical Management Studies." All of this gives a new impetus to students to understand critical issues which contribute to their development and opens the door to view world issues that they have not previously been exposed to, for example, visionary videos on the outcome of the Indian elections, the works of David Korten and many others. The major objectives of the Brown Bag Seminar Series are: (1). Define and interrogate an understanding of the concept of "Critical Management Studies;" (2). Provide a critical understanding of the concept of "Management," its history and transformation and how it impacts on the day - to - day lives of society at large; (3). Outline and clearly exemplify the problems and challenges of "managing" the public, private and non - governmental sectors; (4). Identify critical differences between "management" and "leadership." (5). Share experiences and knowledge on innovative initiatives in management studies; (6). Stimulate innovative thinking and actions in management and governance; (7). Build a framework and a network of collaboration for the improvement of innovation in management, leadership and governance; and (8). Synthesize and crystallize all of these issues in terms of South African and African history, the global political economy and in terms of social issues that confront Africa from the viewpoints of economics, development, business, and social constructs to advance the narrative of Africa Rising.

The founding document of the Regent Business School's Brown Bag Seminar Series by Soni and Karodia (2013: 1 - 3) points out that "all business schools in South Africa and Africa as a whole must offer Critical Management Studies (CMS) as a range of alternatives to mainstream management theory with a view of to radically transforming management practice. The common core is deep skepticism regarding the moral defensibility and the social and ecological sustainability of the prevailing forms of management and organization. In CMS research, both the practice of teamwork and the mainstream theories that inform it are seen as more problematic. This must be undertaken on the basis of dealing with the oppressive internalization of business values and goals. The resulting conformism suppresses democratic dialogue about the appropriateness of the underlying values and goals. It shows how teamwork routinely reinforces established class and authority hierarchies as well as oppressive gender and ethnic relations. It signifies radical critique in order to avoid socially divisive and ecologically destructive broader patterns and structures that condition local action and conventional wisdom. It has to be acknowledged by business schools that, in developing the critical agenda, CMS has been influenced by contemporary developments beyond business and management studies. In this regard a succession of major natural and social crises has brought into sharp focus issues that previously may have seemed more peripheral, issues such as business ethics, environmentalism, and neo - imperialism. CMS accentuates such sentiments by pointing to how prevailing structures of domination produce a systemic corrosion of moral responsibility when any concern for people or the environment requires justification in terms of its contribution to profitable growth."

On the other hand corporate governance is a hot topic in the private sector and according to Spanhove and Verhoest (2007) "there is a consent and belief that "good governance adds value" and has been highlighted in the private sector by corporate scandals and overt corruption in the public sector and that, these sectors need to meet the challenges of global competition, technological progress and integrated financial markets. Corporate governance is about structures and processes by which organizations are directed, controlled and held to account. It is obvious therefore that the Council on Higher Education (CHE) of South Africa, has a moral responsibility to harness the potential of South African Business Schools to change and, give impetus to the development trajectory of a country that is on the march, 
given its apartheid and colonial history. It must set the agenda and hold the South African Business Schools Association accountable in terms of not high jacking South Africa's and Africa's developmental and business possibilities. It must be halted for purposes of engineering democratic governance that must permeate the MBA agenda in South Africa and its Eurocentric arrogance must be decisively dealt with. In other words the status quo must be broken and new blood must be infused into its corporate system, in terms of rectifying the imbalances created from South Africa's past history of marginalization of people of 'colour' to participate in a meaningful manner.

The system of people of 'colour' being introduced on the basis of 'tokenism' must also be dealt with decisively. There is an urgent need for reform. "The element of the governance cycle is the process of accounting for behaviour and actions" (Mulgan, 2003; Verschuere et al. 2006). The CHE must therefore institute a formal process done through reports and hearings. Accountability is a short - term process by order of external bodies. Moreover the CHE has to institute these accountability mechanisms and processes in order to justify the possible results and outcomes of its audit processes and instituted mechanisms because accountability just as monitoring occur in two directions, horizontally towards minister, parliament and citizens and, vertically towards stakeholders, such as business schools, students, interest groups and customers. There is no other way. One cannot have a recurriculation exercise of MBA's without the $\mathrm{CHE}$ setting the agenda for reform in terms of meeting the business requirements of development and in terms of the type of MBA graduate that must be produced by business schools for South Africa and Africa as a whole. The CHE needs to stamp its authority upon narrow and parochial interests and thus take a quantum leap into the future without let or hindrance.

To conclude this part of the discussion, it is important to elaborate on Pfeffer's (1994) analysis which states that "it basically means recognizing the varying interests and the political landscape and, figuring out what is the point of view, the various power units have on issues of concern and, as to why they have this perspective. In order to achieve good governance the CHE and the South African Association of Business Schools together with Business Schools in general must recognize the interests of different actors. This power must be managed by understanding the power dynamics because, it can be productive and also unproductive and at the same time, the system must also look at the changing power allocations and their influence on the government governance structures." The time has come for South Africa to seriously consider the relationships and dynamics that permeate the MBA landscape within the country.

\section{Rethinking the Role of Global Investment in Africa's Development}

The above theme is vitally important for Africa, given the discussion in this paper thus far, because as Yash Tandon states (2014) that "much hope is placed on foreign direct investment (FDI) to deliver development capital for African countries. FDI is part of the global financial capitalist system, which maintains and reproduces inequality and keeps African states dependent on western countries and financial institutions." FDI cannot get Africa out of their development crisis. This is an illusion of African leaders. Capital is simply savings of the past, used for production along with other factors of production such as land, labour and enterprise. Tandon, in this regard (2014) points out that "it is not the same thing as money because money is a system of credits and debts. Capital, on the other hand is money used to add value to production. The world has become more unequal over the last 50 years and that the rich - poor gap has widened in the last decade. This is also the case in more 'egalitarian states such as Germany, Denmark and Sweden because the rich versus poor welfare gap is growing. Literature does not say that there is no possibility of a 'distributive solution' within the present system, which is structurally engineered to produce inequality. In other words, the political and social forces, even in the west, are weakening in relation to the power of global corporations and a global 'bankocracy'."

In this context, the role of the so - called 'development aid' is totally misunderstood or deliberately misinterpreted Aid is corruption. Why? Asks Tandon (2014) "Because it corrupts government policy and governments have to surrender policy space to the donors and the IMF. What can be more corrupt than that?" It is this type of analysis and critical thinking that is required within the MBA"s of Africa and South Africa. It creates credit lines that place countries at the mercy of these lending agencies, debt is increased and the nation and its people suffer. The rich get richer and the poor get poorer. China can negotiate because it has a huge domestic market and is a strong country with a powerful economy and international presence, but Africa is nowhere near China in negotiating such deals. Most African countries are hostages to the global corporate owners of capital and technology. Global corporations do not act alone and investments are made within the framework of Bilateral Investment Treaties (BIT'S). It is now acknowledged within government circles that BIT's are an excuse in undermining the sovereignty of the capital - receiving countries. According to Tandon (2014) "Bit's invariably provide for extra - territorial rights for the owners of capital, including, typically, protection from expropriation; free transfer of exorbitant profits and royalties; and litigation under the jurisdiction of either the capital exporting countries or international arbitration. Uganda is being subjected to immense pressure by the US government to 
sign a BIT. If signed, it will effectively undermine the sovereign rights of the people of Uganda."

The problem lies at the structural level and at the level of political leadership. The first is economic, the second is political. At the structural level, the problem stems from the global deformation of the capitalist system. But capitalism has no future in Africa. Despite bold efforts to 'Africanize' capitalism in some countries such as South Africa, Kenya and Nigeria, these efforts in the last 50 years have largely failed. There are some (very few) African billionaires but, the rest of the African economies are controlled and dominated by global corporations, especially in mining, commodities, finance and service sectors. Tandon (2014) states that "The post - 1980's liberalization has decimated what little industrialization took place in the preceding 20 years. The much vaunted 'growth' rates in Africa of $5-10$ percent is a conceptual and statistical trick played by global institutions such as the IMF and the World Bank and the ruling elites in Africa. This is the reality and the sooner we wake up to this nefarious plot, the better for Africa and for "Third World" development. It is issues of this nature that need to be included within the ambit of the MBA in order to stimulate critical thinking in a move to consolidate the idea of 'Critical Management Studies.' But if capitalism has no future, socialism is a distant goal. Self reliance and not aid or FDl's is the way forward. In this regard democratic governance and correct political leadership becomes a crucial and critical factor. It is obvious that given this narrative, there has to be a rethink about global investment in Africa.

\section{Some Findings, Recommendations and Conclusions}

The relationship between business schools and their regional business communities, have impacted on the ability of business schools and their parent institutions to act as agents of economic regeneration, to act as 'anchor institutions' impacting negatively on the competitiveness of the African economy. Yet the business school community should be a central part of the solution to the economic challenges faced by Africa and South Africa. The South African Association of Business Schools has technically reneged on its responsibilities and it therefore has a key and major role to play in the process of change. In so doing, it must:

- With the Council on Higher Education in South Africa lead democratic change and break the status quo which has dominated the MBA landscape for far too long.

- It must be involved in developing capacity of the South African business school sector to deliver high quality management education.

- MBA education should for all intents and purposes include the history of education in South Africa brought about by colonialism and the legacy of apartheid.

- Issues of 'Critical Management Studies,' socio - political issues, the global political economy, development mandates and other critical issues that affect African business imperatives must be championed.

- Business schools in South Africa and Africa under the guise of their associations must be in a position to influence policy and engagement between government, the private sector, universities, the business school community and the corporate community.

- Fulfil the role in enhancing the performance and competitiveness of South African business schools.

- Credible, informative, practical and user - friendly research must become the order of the day, in order that recommendations made are practically implementable.

- It must be at the forefront of sound innovation strategies.

- It must form a strategic alliance with African business schools, allow for academic infusion by forging relationships with developing economies and countries.

- The fee regimens have to be drastically reduced.

- They need to address the theme of 'us and them' and, allow open debate; because of its parochial approach; South African business talent that can emanate from the black citizenry of South Africa and black academics is not being given meaningful representation in many forums and, within the realm of sound and sustained debate and discussion.

- Undergraduate training must be emphasized in order to attract the best students to the MBA programme.

- Changes must not damage business schools' abilities to attract students given international competition.

- Research must be focused and young academics and students must be allowed to publish freely and rapidly, and there must be no gate keeping in respect of research with reference to publications.

- Access to MBA studies in South Africa must become a priority because of the history of exclusion of black students, in order to break down the racial superiority of white administrators controlling the MBA programme in South Africa, with particular reference to the traditional former white apartheid institutions. 
- Incorporating indigenous knowledge and its belief and knowledge systems into aspects of the MBA programmes within South Africa, on the basis that indigenous knowledge, its business modalities and, economic possibilities to small businesses, including, it's possible definite contribution that, such indigenous knowledge can make, to all forms of higher education, to society generally and, particularly to the MBA programmes offered in South Africa and the continent, must be very seriously considered for inclusion into the curriculum because, it has been marginalized and excluded from Eurocentric education, in the continent of Africa, including South Africa.

- The Association together with the CHE must address the issue as to why the traditional MBA universities produce limited graduates and as to how these numbers can be increased to deal with the acute and chronic shortage of black managers in fields dominated by whites.

- A more meaningful participation of black professionals within the hierarchy of the association.

- Over regulation by the CHE should be placed on the agenda and its role beyond regulatory issues must be defined and discussed.

- A host of other issues that require interrogation, discussion and debate, within the ambit of reasoned conversation and without unnecessary emotion.

\section{Some Reflections from the Literature}

Killingley (2010) states that "it is important to appreciate the level of internationalization, is of greater significance to business schools than other subjects and that the landscape has changed." In this regard governments around the world are increasingly looking to their higher education systems to drive economic growth, and therefore, one cannot underestimate the role of the MBA to promote this requirement in South Africa. As we have seen in the last decades a changed landscape in the higher education sector of South Africa, given access and democracy, the MBA programmes at traditional universities have been slow in imbibing change parameters. This change becomes vital in order to move from silo thinking that has characterized MBA programmes in South Africa. Change will intensify "competition and provide opportunities for strengthened collaborations globally" (Killingley, 2010). This aspect must be seriously considered by South African education authorities. Given our history, we must become a more open society, but our political discourse seemingly makes us more insular and stymies development and economic growth.

Alix Green (2010) indicates that "moving higher education into business, innovation and skills is a strategy of rationalization of the machinery of government but it is also symbolic in policy terms. This must be undertaken to build capacities, in order to deal with pressing development challenges but, more importantly to compete globally, and therefore universities and private providers of the MBA must be regarded as a core part of any strategy on education." Many universities and private providers of the MBA have good systems and structures in place for speaking to government and to local business. Local enterprise partnerships, the municipal local economic development programmes can be used to build capacity and enterprise development. Business schools can also train SME's. This is where cooperation between universities and private providers of the MBA programmes, is essential, creating a collaborative advantage whereby institutions work together to meet business needs. This is not a feature of the traditional universities in South Africa offering MBA programmes and perhaps, this is because of their traditional understanding of apartheid education and the processes of exclusion. This expectation that applies as much to the traditional South African universities as it does to politicians, policy makers, officials and regulatory bodies that control the MBA programmes.

Our point is simple, in that South Africa is not making the most of the strengths of the Higher Education sector and the private institutions, because of the diversity of the institutions but more importantly to consider the shaping of institutions only from a regulatory framework and thus denying the development trajectory and contribution that all higher institutions can make to South Africa. Government cannot by traditional university education alone, deal with the excessive demands in respect to admission, in terms of the number of limited admission places available at traditional universities. It has to form a compact with approved and recognized private institutions that could fill an important gap that exists. This must be done against the background that, it must support and subsidize students to enter private institutions for educational purposes. This will also allow greater access and will be more cost effective, when one considers that such students would not have to travel, or pay board and lodge, pay lower tuition fees and so on. Such models have been successfully undertaken and used, in other African and Southern African countries. The time has come for South Africa to look very seriously to education models of this nature.

A greater emphasis should be paid by government and all MBA providers in respect to access through the modality of the Recognition of Prior Learning (RPL) because; South Africa is in a state of transition. It's better for the country to 
have a broadly educated and literate society and communities. On the other hand, it must now become an imperative, that there needs to be a very strong representation on the Association of Business Schools by South African business and corporates. This is essential from the perspective of defining what they want from MBA graduates and the opportunities and finance they will provide not to selected schools of their choice, but to all business schools, including private providers that offer MBA programmes and commercial and financial undergraduate qualifications. Why they are excluded makes no business sense? There can be no plausible explanation on the part of the South African Association of Business Schools, in this regard. These business and corporate representatives must also provide opportunities for MBA students through work integrated learning and invest largely into scholarships at both universities and private MBA providers. The ball has to be placed in their court of business and corporates, by the government and the South African Association of Business Schools.

Alongside the corporate role that universities and private providers can play in local economic development Green (2010) shows that there is "another dimension that should be considered, in that, universities are academic institutions, with a wealth of different approaches to knowledge expressed within their disciplines and what can be done to mobilize these different approaches in an integrated way, to address the social and economic issues our communities face. What about the role of history and heritage in sustainable development"? This has been precisely the thrust of this paper, and to this end, it has been argued that, the use of the past to imagine and design more sustainable futures and therefore, using good records, capturing institutional memory and understanding history can all help business map out better strategies for ongoing development of a country like South Africa and many in the continent, in respect to ongoing economic and general development. What is needed is commitment and imagination, both at corporate and at a discipline level, including government, to find the points of integration between local and national agendas.

\section{Synthesis of Culture and Appropriate Technology}

The MBA programmes in South Africa historically and even today has paid scant reference to the concepts of synthesizing culture and appropriate technology into the MBA discourse. This is important from the perspective of demystifying Eurocentric concepts that dominate educational imperatives in Africa. Every culture, if it is to continue, must form patterns for the education and training of oncoming generations. It must be able to synthesize culture, indigenous and traditional knowledge with appropriate western technology to suit its conditions and frames of reference. Fasheh (1982: 6) states "that the world is heading to a peak of cultural changes and cultural awareness. Training can be used to stress one's own culture, with its special and beautiful characteristics. At the same time it can be used to make one aware of the drawbacks in one's own culture and to try to overcome them." In other words, training should be used to point out the strengths and weaknesses of one's own culture. Teaching which is detached from cultural aspects and conducted in a purely abstract, symbolic and meaningless way is not only useless, but also very harmful to society, to training itself and to future generations. This is precisely what western and European education dominance has not taken into consideration in Africa. In many ways, this status quo is maintained and has to be reviewed in a critical manner, in order to improve the self - worth of the African, which was trampled upon by colonialism and apartheid education legacies.

Colonization has implied the underdevelopment of most so - called 'developing countries. Underdevelopment is just not an economic process. Foreign domination also caused major structural problems and thus reinforced underdevelopment in all facets of African life. African culture was ignored or despised by the colonial settler, and all life was negated, reduced and destroyed; education was presented as the White man's creation and ability. Cultural affirmation should have formed part of the struggle against underdevelopment and a combat against racial and colonial prejudice. In all underdeveloped regions, it is necessary to encourage an understanding that the people have been, and will be, capable of developing education and other forms of engagement by themselves. This was denied to the African people.

Culture together with its indigenous knowledge systems could thus be redefined in terms of its relationship to the dominant social formations and power relations in society. This 'politicized' concept of culture would include the relationship between ideology and the socio - economic system. In a country like South Africa, where the political and economic dominance from the past and which still persists largely today in the economic sphere, of one group over all others had been and has been entrenched for so long and therefore, the constructs and concepts of the MBA programme, in terms of power and conflict are central to a discussion on culture. Girous (1981: 26) describes a 'politicized' notion of culture more fully thus "Culture, in this sense, would be defined not simply as life's experiences functioning within the context of historically located structures and social formations but as 'lived antagonistic relations' situated within a complex of socio - political institutions and social forms that limit as well as enable human actions." Therefore, culture is more than simply the expression of what grows out of the experience of people in their daily social 
and economic roles. The culture of people encompasses their experiences in the struggle for both political and economic power and their opposition to economic constraints that prevail. This has been the misunderstood reality in South Africa and in many ways reinforced by the government of the day and its institutions. The government therefore, has to intervene decisively and rapidly, if it wants to empower the black citizen through education and, thus deal decisively with the status quo perpetuated by those with self - interest.

It follows, therefore, that totality involves the understanding of any fact or situation in its historical, socio economic, political and cultural context. Knowledge does not exist apart from human consciousness; it is produced by us collectively searching and trying to make sense of our world. Frankenstein (1983: 185) states that "the rationality basic to science and technology disappears under the extraordinary effects of technology itself, and its place is taken by myth making irrationalism." People begin thinking and acting according to the prescriptions they receive daily from the communications media rather than in response to their dialectical relationships with the world. Technology becomes a species of new divinity to which people create a cult of worship." This is precisely what colonialism and apartheid achieved and the West controls the media and has successfully manipulated all debates and thus conditioned the mind of the African. This is what MBA discourse has achieved in South Africa and continues to do even today.

The awe created by both the apparent complexities of technology and the superficially wonderful concrete changes it has made in daily life. Must be countered by showing people that they can understand how technology works and in whose interest it is applied. Critical education must challenge and expose the contradictions in society's definition of 'progress' and the 'good life.' Technology that Africa and South Africa cannot disengage from, in terms of much required development initiatives, business advancement and entrepreneurship, must be incorporated selectively and appropriately with the indigenous culture, knowledge and traditions to create meaningful progress and the good life. A problematizing reality approach as a starting point is in itself already a confidence - creating activity. Problematizing reality, reinforced by cultural, social and individual collective confidence - stimulating activities, will contribute substantially to emancipatory higher education and training in South Africa and Africa, in order to enable students, academics, administrators, government, associations and people to understand, develop and use business education as an important tool in the process of grasping educational reality, the reality of its nature and of society. It stands to reason, therefore, that wants, needs and positions must be very highly regarded in any MBA programme that is attempting to modify their behaviour.

This paper, it is hoped, may in some way, contribute to the understanding of the MBA higher education dynamic in terms of indigenous tradition and knowledge and the influence that selective and appropriate technology could make upon that direction and progress of MBA education in Africa as a whole. One of the essential functions of theory is to help the mind transcend human limitation. One of the most obvious achievements of modern scientific theory is its revelation of a whole array of causal connections which are quite staggering to the eye of common sense. Amuah (1989: 2) noted that "theory serves to place events in a wider causal context than that provided by common sense. But once a particular theoretical idiom has been developed, it tends to direct people's attention towards certain kinds of causal linkage and away from others," as has occurred historically within MBA programmes in South Africa. Most African traditional cultures have adopted a personal idiom as the basis of their attempt to understand the world, which had not been allowed to surface and contribute to development, economics, financial issues and business acumen because of the historic status quo that still largely persists today within the country.

The issue arises, are these traditional notions of cause merely arte - facts of the prevailing theoretical idiom, fantasies with no basis of reality? Or are they responses to features of people's experiences which, in some sense, are really there? Although these notions are ones to which people are not predisposed by the prevailing theoretical idiom, they also register certain important features of the objective simulation. Over much of Africa we deal with small but relatively self - contained communities. These are the rank of social units that have helped Africans achieve equilibrium with all facets of life, including retarding and hazardous factors. Amuah (1989: 3) further states that "scientific method is undoubtedly the surest and most efficient tool for arriving at beliefs that are successful in this respect; however, it is not the only way of arriving at such beliefs. Given the basic process of theory - making and environmental stability which gives theory plenty of time to adjust to experience. A people's belief system may come to grasp, even in the absence of scientific method, a significant range of common sense which Eurocentric policy thinking has blatantly undermined, buried and disregarded. It is because traditional beliefs demonstrated the truth of this that, it seems apt to extend to them the label 'empirical' and not grounded in theory."

The relation between common sense and theory are essentially the same as they are in western society. That is, common sense is the handiest and most economical tool for coping with a wide range of circumstances in everyday life. Nevertheless, there are certain circumstances that can only be coped with in terms of wider causal vision that common sense provides. Thus, in these circumstances there is a jump to theoretical thinking. In this regard Amuah (1989: 4) emphasizes that "it has cast doubt on most of the well - known dichotomies used to conceptualize the difference between 
scientific and traditional African thought: intellectual versus emotional; rational versus mystical; reality - oriented versus fantasy - oriented; casually - oriented versus supernaturally - oriented; empirical versus non - empirical; abstract versus concrete; analytical versus non - analytical. All of these are shown to be more or less inappropriate." Amuah (1989: 4) adds that "if one is disturbed by this casting away of established distinctions, it is hoped that it will be accepted when it is realized how far it can pave the way towards making sense of so much that previously appeared senseless."

The aim of this theoretical exposition has been to re - open the bridge between traditional African thinking and modern western science and, the interpretation of all facets of life and interaction that the westerner interprets as the correct frame of reference. The point is that the difference between non - personal and personalized theories is more than anything else a difference in idiom of the explanatory quest. Grasping this point is an essential preliminary to realizing how far the variable dichotomies used in the field and within education by those that perpetuate the status quo, are simply obstacles to understanding and etching upon the minds of people defined differently by them, as being inferior beings. Once grasped bizarre and senseless features of traditional African thinking become immediately comprehensible. Until it is grasped, they remain essentially mysterious. Making the business of personal versus impersonal entities the crux of the difference between African educational theory and science not only blocks the understanding of tradition, it also draws a red herring across the path to an understanding of any science. This is precisely what status quo protagonists have successfully achieved within MBA programmes in South Africa. It is hoped that this paper may provide some useful directions for the improvement of the MBA programme in South Africa. It is hoped also that policy - makers will endeavour to solicit participation in the planning, execution and evaluation of future MBA programmes. There is no doubt that more in depth research is required in this direction. Studies and assessment in MBA programmes and their content in terms of education methodology should become an integral part of recurriculation initiatives and of transformation of the MBA in South Africa. It has to recognize the importance of development, social issues, global political economy, knowledge and skills. The MBA programme in South Africa must be a comprehensive programme based on the process of acceptability, political legitimacy and credibility, in order that democracy, in the interests of the general welfare and the promotion of the public good, becomes the order of the day. Thereby, a conscious effort is required to redress the imbalances of the MBA programme in South Africa.

\section{Pedagogy Pushed into the Background}

A theme out of observation emerges from the reading of business school history is the focus given to pedagogy, in particular how managers learn. Thorpe (2010: 27 - 28) states that "some of the early research showed that much management knowledge derives not from formal methods of teaching but rather from the adoption of a problem centered, learner centered approach to engagement and reflection on work related events. Through such means, learning it was recognized can occur naturally as well as being enhanced through capturing the knowledge and feeding information to participants in a flexible manner. In other words taking people out of their comfort zones offers a direct benefit to organizations creating a link between management education and organizational development." In the early days of business schools, there appeared to be much greater attention paid to pedagogy than is the case today. It has been far too easy to deal with both scale and scope through the adoption of more traditional methods of delivery, which have the effect of distancing staff from students and theory from practice. Given our colonial and apartheid history in South Africa, our traditional universities are steeped in the history of the apartheid past and have found it most difficult to transform into a much needed new paradigm of necessary change and by implication have secured the maintenance of the dreaded status quo, in South Africa. This has to change and it must change rapidly.

It must be recognized that government in South Africa appears to differ very little from organizations, when it comes to not valuing what business school research can offer when ideas are sought as to how particular problems might be tackled. According to Thorpe (2010: 28) "What appears to happen all too frequently is that new studies are commissioned into familiar problems where the knowledge already exists to give robust answers and advice which could form the basis of policy. He adds further that the reason for this is "that government departments are themselves fragmented and disconnected from where knowledge is being produced." Usually, in South Africa, it has been observed by the researchers that government work in respect of research, into a host of social, economic and development issues, at all levels of government, is allocated at a high cost to some of the former white apartheid traditional universities and, to large audit companies. It is mind boggling as to why this type of work is given to audit companies, who do not have the expertise to carry out such work, and often elicit the expertise of outsiders that possess the skills. These companies must stick to audits and finance and be restricted from entering work areas that they do not have the knowledge, experience and expertise to delve into. On the other hand their charges are too exorbitant.

There is a substantial body of knowledge that exists for example, in relation to entrepreneurship, business 
development, knowledge transfer, internationalization, regulation and so on as well as aspects of societal change through business schools' connection with social sciences. These social challenges, sustainability, low carbon futures innovation in science and demography will all potentially impact on a manager's ability to perform in the future and to develop strategies. This knowledge has to be appropriately harnessed for the benefit of all and reconnected to those who need to know, for the benefit of all and for business and the development of South Africa. This has also been one of the thrusts of this paper.

The time has come for change. The time has come to hold those who maintain the status quo accountable. It cannot be business as usual, after twenty years of South African democracy and nearly sixty years of African independence.

\section{Conclusion}

It has not been possible to exhaust a host of issues that make up the subject matter of this paper. It can therefore be concluded that Higher Education in South Africa, which incorporates the MBA programmes offered in South Africa, is a fast - evolving sector and institutions and employers, including the regulatory body, the South African Association of Business Schools, the government and, all stakeholders must open up a forum to discuss and debate, enter into reasoned conversation as concerns the type of MBA programme that must be offered; the regulatory framework has to be revisited to make it user friendly; the issues of access and pricing, the curriculum and so forth require urgent attention. They must all be prepared to adapt and to think creatively, intellectually, without emotion and, attempt to be flexible about necessary changes that are urgently required, in order to serve South Africa and the continent in respect of MBA education and its demands.

Such initiatives will need regular monitoring to ensure that progress is being made. It is obvious that the paper calls for dealing with the anomalies in education caused by colonialism and apartheid legacy. It also calls for an intervention strategy by the CHE, but more importantly it calls for the South African Association of Business Schools to adapt or in the long run die. The ball is in the court of these institutions and there can be no excuse for a proactive stance, in terms of reshaping South African MBA programmes. With their experience and the collective experience of South African Business Schools, both traditional universities and private MBA providers, there has to be discussion of a somewhat less regulated education landscape, for business schools in particular and therefore, South African business schools must be supported in this endeavour, in order to usher necessary changes across the business sector of South Africa. This is long overdue. In other words the paper calls in addition, for more opportunities for South African black students and for indigenous businessmen that, must be created; to maximize local retention of profits and advance the business agenda, which must be vested from the hands of the white minority and the large corporations; it is a call for equal participation in the economy and within the education sector; to raise the level of intermediate and capital goods production. Lastly, it must be fully understood that the MBA must allow for understanding real development which involves a structural transformation and a mind shift, into a new paradigm that must encompass, the economy, society, polity and culture that, will permit the self - generating, and self -perpetuating use and development of the South African people's potential. This development can only occur in South Africa on the basis of and from the people's frontal attack on oppression, poverty, and exploitation that are meted out to them by the dominant classes and their system.

\section{References}

Acton, E. (2012). The Challenges of Globalization. Association of Business Schools 1992 - 2012. University Business. United Kingdom. Pp. $6-12$.

Amuah, I. (1989). Contrast Between African Traditional beliefs and Western Scientific Ways of Thought. Scientific Reasoning Research Institute. Volume 4. Number 2. University of Massachusetts. Amherst. Mass. Pp. 2 - 5.

Association of Business Schools (2012). Business Schools Seizing the Future $1992-2012$. University Business. United Kingdom. Pp. 1 $-67$.

Barnet, R. and Muller, R. (1974). Global Reach. Simon and Schuster. New York. United States of America. pp. $78-79$.

Barrett, S. R. (1968 - 1969). "The Achievement Factor in Igbo Receptivity to Industrialization." The Canadian Review of Sociology and Anthropology. Volume $5-6$. Canada.

Berger. (1982). (In Offiong). Imperialism and Dependency. Obstacles to African Development. Howard University Press. New York. United States of America. p. 22.

Coleman, A. (1982). Nigeria. (In Offiong). Imperialism and Dependency: Obstacles to African Development. Howard University Press. New York. United States of America. P. 116.

Dostaler, I. (2013). The Great Divide between Business School Research and Business Practice. Canadian Journal of Higher Education. 
Volume 43. Number 1. pp $115-128$

Faseh, M. (1982). "Mathematics, Culture, and Authority." FLM Publishing Association. Montreal. Canada. pp. 2 - 8.

Frank, A. G. (1969). Latin America: Underdevelopment or Revolution. New York Monthly Review. United States of America.

Frankenstein, M. (1983). "Critical Mathematics Education: An Application of Paulo Freire's Epistemology." Unpublished Manuscript. University of Massachusetts. pp. $180-185$.

Giroux, H. (1981). "Ideology, Culture, and Process of Schooling." Temple University Press. 26. Philadelphia. United States of America.

Government Governance. (2000). Corporate governance in the public sector, Why and how? Netherlands Ministry of Finance. The Hague. Netherlands. Pp. 5 - 23.

Green, A. (2012). The Challenges of Economic Regeneration. Association of Business Schools 1992 - 2012. University Business. United Kingdom. pp.21 - 24.

Hall, G. (1972). Imperialism Today. International Publishers. New York. United States of America. P. 463.

Karodia, A. M. (2013). The Inextricable Relationship between the Apartheid State and Public Sector Chaos in South Africa. International Journal of Development Research and Quantitative Techniques. 3 (2). Autumn.

Karodia, A. M. (2008). The Impact of Political Legitimacy on the Management of Veterinary Services in the Former State of Bophuthatswana. PhD Thesis. North West University. North West Province. Republic of South Africa.

Killingley, P. (2012). The Global Higher Education Sector to 2020: A Landscape of Change and Challenge. Association of Business Schools 1992 - 2012. University Business. United Kingdom. Pp. $13-16$.

Mohamedbhai, G. Focus on research for development, not academic rankings. Former vice chancellor of the University of Mauritius and former secretary general of the Association of African Universities. Spotlight. Posted July. G_t_mobhai@yahoo.co.uk

Offiong, D. A. (1982). Imperialism and Dependency: Obstacles to African Development. Howard Ūniversity Press. Washington. D.C. United States of America.

Paphitis, S. and Tabensky, P. (2014). Out of the armchair, into the world. Mail and Guardian. Getting Ahead. Supplement. July 4 to 10. Johannesburg. South Africa. Page 2.

Rodney, W. (1974). How Europe Underdeveloped Africa. Howard University Press. Washington. D.C. p. 13.

Rogers, E. M. (1969). Modernization and Peasants. Holt, Rinehart and Winston, Inc. New York. United States of America. pp. 8 - 9.

Shaikh, A; Karodia, A. M; Hay, M; and Soni, P. Africa Rising and the MBA: Need for a Structural Makeover. Press Release 9th July. www.regent.ac.za

Shaikh, A; Karodia, A.M; Hay, M; and Soni, D. (2014). Advocating Africa. Investing in Africa. Regent Business School. Durban. South Africa. www.bluechipjournal.co.za

Soni, D. and Karodia, A. M. (2014). Issues in Critical Management Studies. Brown Bag Seminar Series. Centre for Public Sector Management. Regent Business School. Durban. South Africa. Pp. 1 -3.

Spanhove, J. and Verhoest, K. (2007). Corporate governance versus government governance: translation or adaptation. Institute Voor De Overheid. Katholieke Universiteit. Paper for the EIASM $4^{\text {th }}$ Workshop on Corporate Governance. Brussels. Belgium. November $15-16$.

Tandon, Y. (2014). Rethinking the role of global investment in Africa's development. Africa is not poor: Africa is being looted. Pambazuka / 2014 - 07 - 03. www.yashtandon.com

Thorpe, R. (2012). Drivers for Higher Education. Association of Business Schools 1992 - 2012. University Business. United Kingdom. Pp. $25-28$. 